\title{
Prostate Cancer Cell-Specific BikDDA Delivery by Targeted Polymersomes
}

Umut Can Oz $z^{a, b}$, Zeynep Busra Bolat ${ }^{c}$, Alessandro Poma ${ }^{b}$, Lijuan Guan ${ }^{b}$, Dilek Telcic, Fikrettin Sahin ${ }^{c}$, Giuseppe Battaglia*,b,d,e, Asuman Bozkır*,a

${ }^{a}$ Department of Pharmaceutical Technology, Faculty of Pharmacy, Ankara University, 06560, Ankara, Turkey

bDepartment of Chemistry, University College London, London, UK

'Department of Genetics and Bioengineering, Yeditepe University, 34755, Istanbul, Turkey

${ }^{\mathrm{d}}$ Department of Chemical Engineering, University College London, London, UK

eInstitute of Physics of Living Systems, University College London, London, UK

* Corresponding Author: Asuman Bozkir, E-mail: bozkir@pharmacy.ankara.edu.tr

Address: Department of Pharmaceutical Technology, Faculty of Pharmacy, Ankara University, 06100, Ankara, Turkey. Tel: +90 3122033153 Fax: +90 3122131081.

* Corresponding Author: Giuseppe Battaglia, E-mail:g.battaglia@ucl.ac.uk

Address: Department of Chemistry, University College London, London, 20 Gordon Street, WC1H 0AJ, UK. Tel: +44 2076794688.

\section{Polymersome Mediated Cell-Specific BikDDA Delivery}




\section{Abstract}

In this paper, we report the polymersome-mediated intracellular delivery of pro-apoptotic BikDDA gene using two different peptide-copolymer covalent conjugation strategies specific for prostate cancer targeting. The BikDDA gene was used as a therapeutic agent on prostate cancer cells. The transfection efficiency of BikDDA-loaded poly[oligo(ethyleneglycol) methacrylate]-co-poly[2(diisopropylamino) ethyl methacrylate] $\left(\mathrm{P}\left(\mathrm{OEG}_{10} \mathrm{MA}\right)_{20}-\mathrm{PDPA}_{100}\right)$ polymersomes revealed that they could serve as a suitable non-viral gene transfection tool. The targeted delivery of BikDDA into prostate cancer cells $(\mathrm{LNCaP})$ using polymersomes was successfully carried out by conjugating the PSMA targeting moiety (peptide563) to $\mathrm{P}\left(\mathrm{OEG}_{10} \mathrm{MA}\right)_{20}-\mathrm{PDPA}_{100}$ copolymer using either succinimidyl 4-(N-maleimidomethyl)cyclohexane-1-carboxylate (SMCC) as a bifunctional linker between the thiol-bearing targeting peptide and amino-bearing $\mathrm{P}\left(\mathrm{OEG}_{10} \mathrm{MA}\right)_{20}-\mathrm{PDPA}_{100}$ copolymer or attaching a maleimide-modified targeting peptide onto a thiol-terminated $\mathrm{P}\left(\mathrm{OEG}_{10} \mathrm{MA}\right)_{20}-\mathrm{PDPA}_{100}$ copolymer. The $\mathrm{pH}$ responsive and biocompatible polymersomes, conjugated with peptide563, exhibited an enhanced cellular uptake by LNCaP cells in comparison to the healthy prostate epithelial cell line PNT1A, thus indicating the cell-specific delivery. The increased Bik mRNA expression and cell death in these $\mathrm{LNCaP}$ cells indicates high effectiveness of the targeting polymersomes. According to these results, we believe more efficient gene delivery systems via specifically targeted $\mathrm{pH}$ sensitive polymersomes can be a promising approach and promote the development of novel therapies against prostate cancer.

Keywords: polymersomes, BikDDA, gene delivery, non-viral vector, prostate cancer. 


\section{Introduction}

Prostate cancer is the second most common type of cancer amongst men, with 1.1 million cases recorded worldwide (International Agency for Research on Cancer 2012). Depending on the patient's condition, the treatment of prostate cancer usually includes surgery, radiation therapy, hormone therapy, and/or chemotherapy. Although the conventional combination chemotherapies are usually preferred by physicians, the heterogeneity of prostate cancer cells and toxicity/side effects of drugs on healthy cells are the limiting factors for the treatment (Beer and Raghavan 2000). Therefore, conventional treatment protocols require novel tools to overcome these problems. In order to eliminate the shortcomings of conventional therapies and to replace the standard treatment protocols, employment of the novel nanomaterials ranging from polymer / lipid based particles (e.g. polymersomes, dendrimers, micelles, mesoporous silica particles, and liposomes) to metallic particles (e.g. gold / silver particles), resulting in major improvements. These nanoscale tools can be utilized to offer controlled drug release, enhance drugs' pharmacokinetic profiles, reduce dosage amounts and frequency, augment cell permeability, enable targeted molecule delivery and improve therapeutic efficacy/safety (Banik et al. 2016). From this point of view, the targeted delivery of pro-apoptotic genes and/or drugs to specific cancer cells using nanomaterials represents a promising approach.

The Bik gene is a member of the Bcl-2 pro-apoptotic gene family and functions either by inducing the activity of other pro-apoptotic Bcl-2 genes, or by inhibiting the anti-apoptotic Bcl-2 proteins (Chinnadurai et al. 2009). For this reason, it has been proposed as an apoptosis-potentiating therapeutic gene in human cancers (Zou et al. 2002). BikDD protein, a mutant form of Bik protein, behaves as the constitutively phosphorylated and active form of Bik protein, with an enhanced binding affinity to anti-apoptotic members. When overexpressed in human cancer cells, BikDD 
exhibits a greater pro-apoptotic activity in comparison to its wild type counterpart, leading to a two-fold decrease in tumor growth in in vivo assays (Li et al. 2003; Lang et al. 2011). BikDD not only strongly induces apoptosis, but also inhibits cell proliferation when expressed in breast (Lang et al. 2011), pancreatic (Xie et al. 2007), liver (Li et al. 2010), and prostate cancers (Xie et al. 2014). In a recent work, the inoculation of male nude mice with prostate cancer cells expressing BikDD led to a reduction in tumor growth and extended survival with low toxicity (Xie et al. 2014). To increase the half-life of BikDD protein, the BikDDA gene was generated by mutating serine 124 of BikDD, which was shown to be a more efficient therapeutic gene than BikDD in the treatment of triple-negative breast cancer (Jiao et al. 2014).Thus BikDDA expresses a protein which exhibits an extended half-life and higher therapeutic efficacy than the product codified by the wild-type Bik or mutant BikDD (Jiao et al. 2014). Therefore, in our study, the BikDDA gene was loaded into $\mathrm{pH}$-sensitive polymersomes functionalized with peptides that exhibit high affinity to prostate specific membrane antigen (PSMA) (Shen et al. 2013).

Over the past 20 years, the deepening of the understanding of polymer chemistry allowed scientists to engineer biologically-inspired vesicles formed by the self-assembly of copolymers, also called polymersomes (Discher et al. 1999). These are used for various applications, such as cargo delivery tools [for drugs (Ahmed et al. 2006), genes (Lomas et al. 2010) and proteins (Rameez et al. 2008)], nanoreactors (Gaitzsch et al. 2012), and for diagnostic purposes (Huang et al. 2015). In our previous reports we demonstrated the encapsulation and delivery of pDNA (Lomas et al. 2007, 2008; Oz et al. 2019), mechanisms of cellular entry (Colley et al. 2014), rapid and effic ie nt endosomal release of the payload from PDPA-based polymersomes (Lomas et al. 2010). In addition, this study is the first application of pDNA-loaded targeted polymersomes as non-viral vectors for gene delivery. 
Poly[oligo(ethyleneglycol) methacrylate]-co-poly[2-(diisopropylamino) ethyl methacryla te] $\left(\mathrm{P}\left(\mathrm{OEG}_{10} \mathrm{MA}\right)_{20}-\mathrm{PDPA}_{100}\right.$, also denoted as POEGMA-PDPA) copolymer, was employed to produce polymersomes. The unique properties of $\mathrm{P}\left(\mathrm{OEG}_{10} \mathrm{MA}\right)_{20}-\mathrm{PDPA}_{100}$ in terms of stealth ability in the blood stream and endosomal escape when internalized by cells, allowed developing smart polymersomes for intracellular cargo delivery. Upon cell-specific recognition of polymersomes, internalization by endocytosis occurs where polymersomes are confined in an endosomal membrane, forming early endosomes to start their cytosolic journey. Here, the endosome acid lumen ( $\mathrm{pH} \sim 6$ ) induces the fast disassembly of the polymersomes (PDPA pKa $=6.2$ ). The consequent dramatic increase in the number of species from one vesicle to its building blocks and cargo generates an osmotic shock, which leads to the temporary rupture of the endosomal membrane and the subsequent release of any encapsulated gene into the cytosol (Tian et al. 2015).

Active targeting of the cancer cells mainly exploits the overexpression of a receptor element on the plasma membrane so that the targeted particles are solely internalized by the related cancer cells. Here, we focused our attention on PSMA, a membrane-expressed and prostate-cancer specific target (Elsässer-Beile et al. 2009). To accomplish this objective, a small peptide, "peptide563" (GRFLTGGTGRLLRIS), which exhibits high binding affinity to PSMA (Shen et al. 2013), was conjugated to the $\mathrm{P}\left(\mathrm{OEG}_{10} \mathrm{MA}\right)_{20}-\mathrm{PDPA}_{100}$ copolymer and used to decorate polymersomes for targeting prostate cancer cells.

We recently explored different metal-free conjugation methods for amphiphilic copolymers and concluded that click methods, such as ring-strain promoted azide-alkyne reaction (SPAAC) or Diels-Alder reaction of a 1,2,4-triazoline-3,5-dione (TAD) are extremely selective and effic ie nt (Gaitzsch et al. 2016). However, these methods are sometimes incompatible with pre- 
polymerization approaches in which their insaturation can interfere/or become degraded during radical polymerizations (Gaitzsch et al. 2016). Furthermore, click methods involve the dual modification of the copolymers and the targeted peptide with consequent complications. We observed that in aprotic solvents, the most efficient is the amine/NHS ester reaction, while in protic solvents, the thio/Maleimide is the most effective (Gaitzsch et al. 2016). The latter is also better suited for most proteins and complex peptides where amine bearing lysine residuals are often involved in binding and protein folding while cysteines tend to be only structural and not functional (Ruoslahti 2012). We synthesized maleimide-bearing initiators for both the polymerization of PMPC and POEGMA copolymers(Tian et al. 2015; Gaitzsch et al. 2016) and while this strategy allows the functionalization of peptides, its limited yield permits only few ligands per polymersomes. We improved on this strategy using succinimidyl 4-(Nmaleimidomethyl)cyclohexane-1-carboxylate (SMCC) as a bifunctional linker between the thiolbearing targeting peptide and the amino-bearing $\mathrm{P}\left(\mathrm{OEG}_{10} \mathrm{MA}\right)_{20}-\mathrm{PDPA}_{100}$ copolymer as shown in Figure 1. In addition, a maleimide-modified targeting peptide was attached onto a thiol-terminated $\mathrm{P}\left(\mathrm{OEG}_{10} \mathrm{MA}\right)_{20}-\mathrm{PDPA}_{100}$ copolymer.

Our study demonstrates the targeted delivery potential of $\mathrm{P}\left(\mathrm{OEG}_{10} \mathrm{MA}\right)_{20}-\mathrm{PDPA}_{100}$ polymersomes functionalized with peptide563, on prostate cancer cells. The copolymer-peptide conjugations were successfully carried out utilizing different thio//Maleimide strategies. After BikDDA encapsulation, the targeting and transfection efficacy of the polymersomes were investigated on human prostatic adenocarcinoma cells (LNCaP) and on the PNT1A cell line, which serves as the model for normal prostate epithelium. The transfection efficiency and cell specific delivery of the peptide563 modified $\mathrm{P}\left(\mathrm{OEG}_{10} \mathrm{MA}\right)_{20}$ - $\mathrm{PDPA}_{100}$ polymersomes was compared with pristine polymersomes to reveal the ability of cell specific gene delivery. 


\section{Materials and methods}

\subsection{Synthesis of $\mathrm{P}\left(\mathrm{OEG}_{10} \mathrm{MA}\right)_{20}-\mathrm{PDPA}_{100}, \mathrm{PDPA}_{100}-\mathrm{P}\left(\mathrm{OEG}_{10} \mathrm{MA}\right)_{20}-\mathrm{S}-\mathrm{S}-\mathrm{P}\left(\mathrm{OEG}_{10} \mathrm{MA}\right)_{20}$ - $\mathrm{PDPA}_{100}$ and $\mathrm{NH}_{2}-\mathrm{P}\left(\mathrm{OEG}_{10} \mathrm{MA}\right)_{20}-\mathrm{PDPA100}$ copolymers}

For the $\mathrm{P}\left(\mathrm{OEG}_{10} \mathrm{MA}\right)_{20}-\mathrm{PDPA}_{100}\left(P_{1}\right)$ synthesis (Figure S1a), the ATRP initiator ME-Br (0.194 mmol, 1 eq.) and $\mathrm{OEG}_{10} \mathrm{MA}(1.940 \mathrm{~g}, 3.88 \mathrm{mmol}, 20$ eq.) were placed in a flask. For the $\mathrm{PDPA}_{100}-\mathrm{P}\left(\mathrm{OEG}_{10} \mathrm{MA}\right)_{20}-\mathrm{S}-\mathrm{S}-\mathrm{P}\left(\mathrm{OEG}_{10} \mathrm{MA}\right)_{20}-\mathrm{PDPA}_{100}\left(P_{2}\right)$ synthesis (Figure $\left.\mathrm{S} 2 \mathrm{a}\right)$, bis[2-(2'bromoisobutyryloxy)ethyl]disulfide $(0.034 \mathrm{~g}, 0.075 \mathrm{mmol}, 1$ eq. $)$ and $\mathrm{OEG}_{10} \mathrm{MA}(1.5 \mathrm{~g}, 3 \mathrm{mmol}$, 40 eq.) were placed in a flask. For the amino terminated $\mathrm{NH}_{2}-\mathrm{P}\left(\mathrm{OEG}_{10} \mathrm{MA}\right)_{20}-\mathrm{PDPA}_{100}\left(P_{3}\right)$ synthesis (Figure S3a), 2-aminoethyl 2-bromo-2-methylpropanoate $(0.194 \mathrm{mmol}, 1$ eq.) and $\mathrm{OEG}_{10} \mathrm{MA}(1.940 \mathrm{~g}, 3.88 \mathrm{mmol}, 20 \mathrm{eq}$.) were placed in a flask. Complete dissolution was achieved by adding $\mathrm{MeOH}(1.5 \mathrm{~mL})$ and then purged with $\mathrm{N}_{2}$ for $1 \mathrm{~h}$. Afterwards, a mixture of $\mathrm{CuBr}$ as catalyst $(27.83 \mathrm{mg}, 0.194 \mathrm{mmol}) /$ bpy as ligand $(60.6 \mathrm{mg}, 0.388 \mathrm{mmol})$ was prepared for the $P_{l}$ and $P_{3}$ synthesis and a mixture of $\mathrm{CuBr}(21.52 \mathrm{mg}, 0.15 \mathrm{mmol}) /$ bpy $(49.2 \mathrm{mg}, 0.32 \mathrm{mmol})$ was prepared for the $P_{2}$ synthesis. The solid mixture was added to the solution and was continually stirred overnight at $30{ }^{\circ} \mathrm{C}$. The viscous $\mathrm{POEG}_{10} \mathrm{MA}$ polymerization mixture was sampled and analyzed by ${ }^{1} \mathrm{H}-\mathrm{NMR}$ for the estimation of the conversion. In a separate flask, DPA (4.13 g, $19.4 \mathrm{mmol}, 100$ eq. for $P_{1}$ and $P_{3} ; 3.4 \mathrm{~g}, 15 \mathrm{mmol}, 200$ eq. for $P_{2}$ ) was dissolved in $3.5 \mathrm{~mL}$ of EtOH and purged with $\mathrm{N}_{2}$ for $1 \mathrm{~h}$. After degassing, the DPA solution was added dropwise to the viscous mixture. After $24 \mathrm{~h}$, the flask was opened to the air and diluted with $\mathrm{MeOH}$, which gave a dispersion that gradually turned green due to the oxidized copper catalyst. Then, $100 \mathrm{~mL}$ of EtOH were added, leading to a transparent solution. This was passed through a column of silica to remove the copper catalyst. The resulting solution was concentrated by rotary evaporation and dialyzed 
(MWCO $1 \mathrm{kDa}$ ) against $\mathrm{CHCl}_{3} / \mathrm{MeOH}(3: 1, \mathrm{v} / \mathrm{v})$ two times, then against $\mathrm{MeOH}$ for three times and eventually against $\mathrm{H}_{2} \mathrm{O}$ for four times.

The resulting dispersion was freeze-dried giving a white powder. The resulting copolymer composition was analyzed by ${ }^{1} \mathrm{H}-\mathrm{NMR}$ in $\mathrm{CDCl}_{3}: \mathrm{CD}_{3} \mathrm{OD}(3: 1$, v/v) and the polydispersity was determined by gel permeation chromatography in $\mathrm{H}_{2} \mathrm{O}+0.25 \% \mathrm{v} / \mathrm{v}$ TFA.

\subsection{Reaction of $\mathrm{PDPA}_{100}-\mathrm{P}\left(\mathrm{OEG}_{10} \mathrm{MA}\right)_{20}-\mathrm{S}-\mathrm{S}-\mathrm{P}\left(\mathrm{OEG}_{10} \mathrm{MA}\right)_{20}-\mathrm{PDPA}_{100}$ with maleimide terminated Peptide563}

In a typical procedure (Figure S4), maleimide terminated peptide563 (purchased from Proteogenix $)(2.0 \mathrm{mg}, 0.00087 \mathrm{mmol}, 2$ eq. $)$ and $\mathrm{PDPA}_{100}-\mathrm{P}\left(\mathrm{OEG}_{10} \mathrm{MA}\right)_{20}-\mathrm{S}-\mathrm{S}-\mathrm{P}\left(\mathrm{OEG}_{10} \mathrm{MA}\right)_{20}-$ PDPA $_{100}(27.0 \mathrm{mg}, 0.00044 \mathrm{mmol}, 1$ eq.) were placed in a flask. A complete dissolution was obtained by adding EtOH (4 mL) then purged with $\mathrm{N}_{2}$ for $1 \mathrm{~h}$. Afterwards, triphenylphosphine (0.2 $\mathrm{mg}, 0.00076 \mathrm{mmol}, 1.5$ eq.) was added and the solution was continually stirred for $48 \mathrm{~h}$ at room temperature. Then, the solution was passed through silica and dialyzed (MWCO $10 \mathrm{kDa})$ against $\mathrm{EtOH}$ (two times) and then against $\mathrm{H}_{2} \mathrm{O}$ (three times).

The final dispersion of the conjugate was freeze-dried and conjugation was confirmed by fluorescence detection via HPLC analysis.

\subsection{Reaction of $\mathrm{NH}_{2}-\mathrm{P}\left(\mathrm{OEG}_{10} \mathrm{MA}\right)_{20}-\mathrm{PDPA}_{100}$ with cysteine terminated Peptide563 via SMCC}

First the synthesis and purification of cysteine terminated peptide563 were performed according to previously published procedures (Mustapa et al. 2009) and confirmed by Waters Micromass MALDI-TOF (Figure S6) and analytical HPLC (Figure S7). 
Peptide conjugation to $\mathrm{H}_{2} \mathrm{~N}-\mathrm{P}\left(\mathrm{OEG}_{10} \mathrm{MA}\right)_{20}-\mathrm{PDPA}_{100}$ was carried out via using succinimidyl 4[N-maleimidomethyl]cyclohexane-1-carboxylate (SMCC) (Figure 1). SMCC exhibits thiol and amino sensitive groups on opposite sides of its structure; therefore, as a first step $\mathrm{H}_{2} \mathrm{~N}$ $\mathrm{P}\left(\mathrm{OEG}_{10} \mathrm{MA}\right)_{20}-\mathrm{PDPA}_{100}(0.0075 \mathrm{mmol}$, 1eq) was dissolved in $2 \mathrm{~mL}$ of DMF and purged with nitrogen for 1 hour. Freshly prepared SMCC $(0.015 \mathrm{mmol}$, 2eq) solution in $0.5 \mathrm{~mL}$ of DMF was added to the polymer solution and purged with nitrogen 30 min more. A few drops of N,Ndiisopropylethylamine (DIPEA) were added to the solution and left to react for $2 \mathrm{~h}$ at $25^{\circ} \mathrm{C}$. Then, purification was carried out by dialysis (MWCO $1 \mathrm{kDa}$ ) against DCM for two days, during which time the dialysis medium was changed four times to remove the non-reacted SMCC. The product was dissolved in DMF again after DCM was evaporated from purified product by rotary evaporation.

In the second step of conjugation, targeting peptide sequence (powder form, 2 eq) was added in SMCC- $\mathrm{H}_{2} \mathrm{~N}-\mathrm{P}\left(\mathrm{OEG}_{10} \mathrm{MA}\right)_{20}-\mathrm{PDPA}_{100}$ (1eq) solution in DMF and purged with nitrogen for $1 \mathrm{~h}$ then $\mathrm{PPh} 3$ (1.5 eq) was added in solution and left to react over $48 \mathrm{~h}$ under nitrogen. The peptide conjugated polymer was purified by dialysis (MWCO 10kDa) against $\mathrm{pH} 7.4$ water for two days (dialysis medium was changed four times) and final product was obtained after freeze drying.

\subsection{Preparation, purification and characterization of polymersomes}

The polymersome formulations were prepared using the $\mathrm{pH}$-switch method. To prepare the peptide563 targeted polymersome (tPS) formulations, a mixture of peptide563- $\mathrm{P}\left(\mathrm{OEG}_{10} \mathrm{MA}\right)_{20-}$ $\mathrm{PDPA}_{100} / \mathrm{ME}-\mathrm{P}\left(\mathrm{OEG}_{10} \mathrm{MA}\right)_{20}-\mathrm{PDPA}_{100}$ at 1:9 ratio was used. Following a typical procedure, first, the polymer mixture was dissolved $(10 \mathrm{mg} / \mathrm{mL})$ in a $\mathrm{pH} 2.0$ phosphate buffered saline (PBS). The $\mathrm{pH}$ was increased by adding $0.5 \mathrm{M} \mathrm{NaOH}$ at a $10 \mu \mathrm{L} / \mathrm{min}$ rate via a syringe pump. When the $\mathrm{pH}$ 
reached 6.0, the flow rate of $\mathrm{pH} 2.0 \mathrm{PBS}$ was decreased to $5 \mu \mathrm{L} / \mathrm{min}$ until the $\mathrm{pH}$ reached 7.4. After this process, the dispersion was stirred for 1 day to stabilize the vesicles.

The polymersome formulation was then purified by sonicating the cloudy dispersion for 45 min to ensure that all the tubular formations were broken down into spherical vesicles, and then all the remaining aggregates and large particles were removed by centrifugation (1000 g, $10 \mathrm{~min})$. The vesicle dispersion was purified by SEC via a Sepharose $4 \mathrm{~B}$ column to remove micellar structures.

The polymer concentration was evaluated after the purification step by dissolving the polymer in PBS pH 2.0 and performing a UV-Vis spectroscopy measurement at $220 \mathrm{~nm}$. The average diameter size and polydispersity of polymersomes $(0.5 \mathrm{mg} / \mathrm{mL})$ were analyzed using the Dynamic Light Scattering (DLS) method and the zeta potential was analyzed with electrophoretic light scattering method to assess the surface charge in 5 replicates.

The size, surface morphology and topology of polymersomes were visualized via Transmission Electron Microscopy (TEM, Tecnai 10, Philips, Netherlands) at $80 \mathrm{kV}$. The visualization was carried out on the phosphotungustic acid (PTA) stained polymersomes (Lopresti et al. 2011), in which $5 \mu \mathrm{L}$ of polymersome dispersion $(0.5 \mathrm{mg} / \mathrm{mL})$ was deposited onto glow-discharged carbon coated copper grids for $1 \mathrm{~min}$. A $0.75 \%(\mathrm{w} / \mathrm{v})$ PTA solution at $\mathrm{pH} 7.4$ was used for staining. The excess amounts of solutions were blotted with filter paper and samples were dried under vacuum after each step.

\subsection{Encapsulation of BikDDA into $\mathrm{P}\left(\mathrm{OEG}_{10} \mathrm{MA}\right)_{20}$-PDPA 100 polymersomes}

BikDDA loading into polymersomes was performed using the electroporation method (Wang et al. 2012) previously optimized by our group to encapsulate various biomacromolecules inside 
polymersomes. Firstly, BikDDA gene was labeled with Cyanine5 (Cy5) via Label IT Tracker Cy5 Kit to detect very low concentrations using a fluorometer. The standard curve of the BikDDA gene was conducted using fluorescence spectroscopy (Varian Cary Eclipse) with an excitation wavelength of $635 \mathrm{~nm}$ and emission wavelength of $674 \mathrm{~nm}$. Labeling of BikDDA with Cy5 was achieved according to the protocol provided by the supplier. The labeling reagent and BikDDA were mixed at 0.5:1 (v/w) ratio in presence of labeling buffer and incubated for $1.5 \mathrm{~h}$ at $37^{\circ} \mathrm{C}$. After the reaction was completed, unreacted labeling reagent was removed by EtOH precipitation. The obtained labeled BikDDA pellet was washed with $70 \% \mathrm{EtOH}$ and the sample was air dried for $1.5 \mathrm{~h}$. Final labeled BikDDA was diluted to desired volume with sterile PBS.

The BikDDA gene was encapsulated into the vesicles using the electroporation method (Eppendorf electroporator 2510 equipped with $400 \mu \mathrm{L}$ sterile cuvette). A current of $2500 \mathrm{~V}$ was applied five times with $30 \mathrm{~s}$ between each application. The polymersome dispersion was stored for at least $1 \mathrm{~h}$ at $4{ }^{\circ} \mathrm{C}$ without any manipulation to allow for the pores on the surface to completely heal.

The non-encapsulated BikDDA was removed from the polymersome dispersion via DNA digestion. In this process, $65 \mu \mathrm{L}$ of $10 \times$ reaction buffer [100 mM TrisHCl (pH 7.5), $25 \mathrm{mM} \mathrm{MgCl}$, and $5 \mathrm{mM} \mathrm{CaCl} 2$, $18 \mu \mathrm{L}$ DNAse I (90 IU) and $167 \mu \mathrm{L}$ DPBS $\left(\mathrm{Ca}^{2+} / \mathrm{Mg}^{2+}\right.$ free) were mixed with the electroporated polymersome dispersion ( $400 \mu \mathrm{L}, 0.045 \mathrm{mg} / \mathrm{mL}$ BikDDA) and incubated for 10 min at $37{ }^{\circ} \mathrm{C}$ to allow for the phosphodiester bonds in the DNA backbone to be digested. Then, the polymersome dispersion was purified from the non-encapsulated BikDDA residues and DNAse I by passing through Sepharose $4 \mathrm{~B}$ column. The obtained purified polymersome dispersion was stored at $4{ }^{\circ} \mathrm{C}$ before further analysis. 
After purification, the encapsulated amount of BikDDA was analyzed by a fluorometer and presented as number of BikDDA per polymersome (Wang et al. 2012).

\subsection{Site-directed mutagenesis}

Site-directed mutagenesis was performed according to the manufacturer's protocol using QuikChange Lightning Site-Directed Mutagenesis Kit. First, threonine 33 and serine 35 of pEGFPBik plasmid were changed to aspartic acid to obtain BikDD using 5'GTTCTTGGCATGGACGACGATGAAGAGGACC-3' and 5'-GGTCCTCTTCATCGTCGTCCATGCCAAGAAC-3 primers and then the serine 124 of BikDD was changed to alanine using the 5'-AACATAATGAGGTTCTGGAGAGCCCC-GAACCCC-3' and 5'GGGGTTCGGGGCTCTCCAGAACCTCATTATGTT-3' primers. The sequences of the BikDDA mutant construct was confirmed by automated sequencing (Figure S8).

\subsection{Cell culture and measurement of cell viability}

PNT1A and LNCaP cells were maintained in RPMI 1640 medium supplemented with $10 \%$ fetal bovine serum.

Cell viability was assessed colorimetrically using an MTS reagent in LNCaP and PNT1A cells treated with $25,50,75$ and $100 \mu \mathrm{g} / \mathrm{mL}$ concentrations of $\mathrm{P}\left(\mathrm{OEG}_{10} \mathrm{MA}\right)_{20}-\mathrm{PDPA}_{100}$ polymersomes. In addition, the cell viability of LNCaP cells transfected with the BikDDA gene loaded tPS (tPSBikDDA) was evaluated after $72 \mathrm{~h}$. For this purpose, cells were seeded in 96 -well plates at $5 \times 10^{3}$ cells/well and subjected to an MTS assay at each $24 \mathrm{~h}$ interval following the standard protocol provided by the manufacturer. The absorbance was read with a microplate reader at $490 \mathrm{~nm}$. 


\subsection{Fluorescence microscopy}

LNCaP and PNT1A $\left(1 \times 10^{4}\right.$ cells/well $)$ cell lines were treated with $25,50,75$ and $100 \mu \mathrm{g} / \mathrm{mL}$ concentrations of PS-BikDDA or tPS-BikDDA. The cell images (from at least four random fields covering a minimum of 100 cells/field) were taken under the Zeiss Axio Vert.A1 fluorescence microscope at $20 \times$ objective at 24,48 and $72 \mathrm{~h}$ following the treatment. The transfection efficiency was presented as the percentage ratio of EGFP expressing cells to the total number of cells in the field.

\subsection{Confocal microscopy and flow cytometry}

LNCaP and PNT1A $\left(3 \times 10^{6}\right.$ cells $\left./ \mathrm{m}^{2}\right)$ cells were treated with $600 \mu \mathrm{g} / \mathrm{mL}$ of tPS in RPMI 1640 . After $4 \mathrm{~h}$ incubation, for confocal microscopy cell monolayers were washed in serum free medium, fixed with $2 \%$ formaldehyde, stained with $5 \mu \mathrm{g} / \mathrm{mL}$ of DAPI and visualized with a Zeiss LSM 700 confocal microscope. For flow cytometry, after analysis the incubation cells were dislodged from their substratum via trypsinization and analyzed immediately in a BD FACS Calibur flow cytometer.

\subsection{Quantitative reverse transcription PCR (qRT-PCR)}

The relative Bik/18sRNA mRNA expression using real time PCR in LNCaP cell line transfected with tPS-BikDDA, empty PS and non-treated LNCaP cells (control) were analyzed as described previously(Erdem et al. 2014). Primer sequences used for Bik were sense 5'GAGACATCTTGATGGAGACC-3' and antisense 5'-TCTAAGAACATCCCTGATGT-3'. As a housekeeping gene to ensure equal loading 18sRNA reference gene was used and the data was analyzed using 18sRNA as normalization control. 


\subsection{Statistical analysis}

Statistical analyses were performed using GraphPad Prism Software (version 6.01). Error bars were obtained represent the standard error of the mean, and the data sets were compared using $\mathrm{t}$ test. The significance level was set at $\mathrm{p}<0.05$.

\section{Results and discussion}

\subsection{Synthesis of $P\left(O E G_{10} M A\right)_{20}-P_{D P A} A_{100}$ copolymers and peptide conjugation strategies}

The synthesis of $\mathrm{P}\left(\mathrm{OEG}_{10} \mathrm{MA}\right)_{20}-\mathrm{PDPA}_{100}$ copolymers (plain and bearing an amino or thiol end groups) was carried out according to previously published procedures (Lomas et al. 2007; SimónGracia et al. 2016). ${ }^{1} \mathrm{H}-\mathrm{NMR}$ analyses were performed to confirm the molecular structures of the polymers (Figure S1b, S2b and S3b). The molecular weight and distribution were determined by gel permeation chromatography (GPC) analysis, and a size distribution was observed with a polydispersity index of 1.2 (Figure S5).

After synthesis, the copolymers were conjugated with peptides via two different strategies. For the first reaction, thiol terminated polymers were conjugated with a PMSA-targeting peptide sequence (Tamra-GRFLTGGTGRLLRISK-Maleimide), exploiting the one-pot synthesis reaction between the thiol group of the copolymer and the maleimide group of the peptide sequence (Gaitzsch et al. 2016; Simón-Gracia et al. 2016). As shown in Figure 2a, the P(OEG10MA)20-PDPA100 copolymer does not exhibit any florescence intensity, while the fluorescence peak of the Tamra-bearing peptide sequence was observed during the 13th min of analysis. The peptide conjugation to copolymer was confirmed (Figure 2) by detecting the fluorescence peak of Tamra by HPLC analysis using the fluorescence detector set at $541 \mathrm{~nm}$ excitation and $568 \mathrm{~nm}$ emission 
wavelengths. The disappearance of the peptide's fluorescence peak at 13th min and observation of the strong fluorescence peak in the 18th min of the HPLC chromatogram (Figure 2a) of the peptidecopolymer conjugation reaction product, although the POEGMA-PDPA copolymer itself has no fluorescence signal, suggests that the Tamra-bearing peptide sequence was successfully conjugated to the copolymer. As the second conjugation strategy, the $\mathrm{NH}_{2}-\mathrm{P}\left(\mathrm{OEG}_{10} \mathrm{MA}\right)_{20^{-}}$ PDPA $_{100}$ copolymer was primarily reacted with the succinimide group of SMCC by the using NHS ester amidification reaction in DMF to functionalize the copolymer with the maleimide group, then purified by dialysis to remove unreacted SMCC. After this process, the purified copolymer product bearing maleimide group, was conjugated with synthesized cysteine terminated peptide563 via thiol-maleimide click reaction, in DMF again (Figure 1). HPLC analyses were performed to reveal the conjugation by setting the fluorescence detector to detect phenylalanine's excitation (257 $\mathrm{nm}$ ) and emission $(282 \mathrm{~nm})$ wavelengths. The disappearance of the peptide's fluorescence peak at the 13th min and observation of the strong fluorescence peak in the 17th $\min$ of the HPLC chromatogram (Figure 2b) of the peptide-copolymer conjugation reaction product confirms the peptide-copolymer conjugation and indicates the successful utilization of SMCC as a linker for peptide-copolymer conjugation. The reason for the shifting of fluorescence intensity peaks from $\sim 13 \mathrm{~min}$, to $\sim 17$ and $18 \mathrm{~min}$ (Figure 2a-b) is the increment of the total molecular weight after fluorescent peptide sequences were conjugated with copolymers.

The aim of proposing two counter-approaches for the same reaction is to bring a deeper insight to the commonly utilized thiol-maleimide conjugation strategy through presence of the same functional groups on different moieties and to reveal the application potential of SMCC as a crosslinker for conjugation compared to direct conjugation. Among the peptide-copolymer conjugation approaches, the advantage of using SMCC is to eliminate the challenges of maleimide 
terminated polymer synthesis, such as the necessity of protecting the maleimide group. However, the application of direct thiol-maleimide reaction for peptide-copolymer coupling was found to be advantageous compared to SMCC as a crosslinker, considering that the whole conjugation is completed in one-pot synthesis with higher yields and precludes the possibility of undesired reaction pathways leading to byproducts. Although we successfully achieved the synthesis of peptide-copolymer conjugates with both strategies, we preferred the utilization of the one pot synthesis thiol-maleimide coupling for further peptide-copolymer conjugations. Apart from the conjugation strategy, prostate cancer targeted polymersomes were formulated with TamraPeptide563-P(OEG $\left.{ }_{10} \mathrm{MA}\right)_{20}-\mathrm{PDPA}_{100}$ conjugates since the presence of Tamra creates strong fluorescence intensity that is necessary in carrying out further microscopy and flow cytometry analyses.

\subsection{Self-Assembly, BikDDA loading and characterization of polymersomes}

The preparations for the self-assembly $\mathrm{P}\left(\mathrm{OEG}_{10} \mathrm{MA}\right)_{20}-\mathrm{PDPA}_{100}$ polymersomes (PS) and peptide functionalized polymersomes (tPS) were all carried out using the $\mathrm{pH}$ switch method (Robertson et al. 2016) as presented in Figure 3. The mass ratio of targeting peptide to the $\mathrm{P}\left(\mathrm{OEG} \mathrm{H}_{10} \mathrm{MA}\right)_{20-}$ PDPA $_{100}$ copolymer used during the self-assembly was $10 \%(w / w)$. After the vesicle-formation process, the polymersomes were sonicated and purified by centrifugation and size exclusion chromatography (SEC) was used to eliminate unwanted structures. The spherical vesicular structure of polymersomes was confirmed by transmission emission microscope (TEM) imaging (Figure $4 \mathrm{a}, 4 \mathrm{~b}$ ). The average polymersome diameter, measured by dynamic light scattering (DLS), was $181.6 \pm 3.4 \mathrm{~nm}$ for PS-BikDDA and $205.8 \pm 2.5 \mathrm{~nm}$ for tPS-BikDDA (Figure 4c, 4d), suggesting non-significant differences, which is in agreement with previous reports (Simón-Gracia et al. 
2016). The polymersome surface was assessed by zeta potential analysis at $25 \pm 0.5{ }^{\circ} \mathrm{C}$, was $1.54 \pm 0.31 \mathrm{mV}$ for PS-BikDDA and $-2.49 \pm 0.18$ for tPS-BikDDA to be neutral for all formulations

Hence, we can infer that polymersome cellular uptake is controlled by the binding of the given peptide rather than unspecific interactions. The encapsulated amount of Cy5-labelled pEGFPBikDDA plasmid into polymersomes was determined by HPLC using fluorescence detection, which showed the number of encapsulated BikDDA per polymersome as 1.2 for PS and tPS. The final BikDDA and polymer concentrations are presented in Table S2.

\subsection{Effect of $P\left(O E G_{10} M A\right)_{20}-P_{P P A} A_{100}$ polymersomes on cell viability}

An MTS assay was used to measure the cell viability of the PNT1A and LNCaP cell lines treated with different concentrations of $\mathrm{P}\left(\mathrm{OEG}_{10} \mathrm{MA}\right)_{20}-\mathrm{PDPA}_{100}$ polymersomes. The results revealed no detectable toxicity of polymersomes toward all the cell models at all concentrations (Figure 5a$5 b)$ throughout the time course of the experiments (72h).

The cytotoxicity assay results showed that $\mathrm{P}\left(\mathrm{OEG}_{10} \mathrm{MA}\right)_{20}-\mathrm{PDPA}_{100}$ polymersomes did not exhibit any significant cytotoxicity on the PNT1A and LNCaP cell lines, confirming the biocompatibility of the vesicles as reported in earlier studies (Lomas et al. 2007).

\subsection{Prostate cancer targeting specificity of tPS}

Peptide563 conjugated $\mathrm{P}\left(\mathrm{OEG}_{10} \mathrm{MA}\right)_{20}$-PDPA 100 polymersomes (tPS) have a high binding affinity to PSMA. The specificity and affinity of tPS were analyzed in PSMA-expressing LNCaP cells and negative control PNT1A cells using confocal microscopy and flow cytometry. Confocal images of the PNT1A and LNCaP cell lines treated with $600 \mu \mathrm{g} / \mathrm{mL}$ of tPS for $4 \mathrm{~h}$ show that tPS bound strongly only to LNCaP cells (Figure 6a). The confirmation of these results with flow cytometry 
analysis revealed that cellular uptake in PNT1A cell lines treated with tPS was only 3.17\%, whereas the prostate cancer cell line $\mathrm{LNCaP}$ exhibited $46.72 \%$ cellular uptake for the same polymersomes (Figure 6b).

\subsection{Gene transfection efficiency of $P\left(O_{10} M A\right)_{20}$-PDPA $A_{100}$ polymersomes into LNCaP cells}

To investigate the potential of $\mathrm{P}\left(\mathrm{OEG}_{10} \mathrm{MA}\right)_{20}-\mathrm{PDPA}_{100}$ polymersome as a gene transfection agent, we encapsulated the BikDDA gene in the $\mathrm{P}\left(\mathrm{OEG}_{10} \mathrm{MA}\right)_{20}-\mathrm{PDPA}_{100}$ polymersome. The gene transfer efficiency of this polymersome was tested with the plasmid DNA which contains the reported gene EGFP (encoding the enhanced green florescent protein) and BikDDA, the gene of interest. The formulated PS and tPS was tested for its gene delivery efficiency by incubation of LNCaP cells with PS-BikDDA (BikDDA encapsulated PS) and tPS-BikDDA (BikDDA encapsulated tPS). The BikDDA gene transfection efficiency of PS-BikDDA polymersome was then compared to tPS-BikDDA polymersome on LNCaP cell line for $72 \mathrm{~h}$. Cells expressing EGFP imaged under fluorescence microscopy showed that the cells treated with PS-BikDDA ( 5\%) resulted in lower EGFP expression levels than tPS-BikDDA $(\sim 19 \%)$ at $72 \mathrm{~h}$ (Figure $7 \mathrm{~b})$. The quantification of fluorescent images for the EGFP-positive LNCaP cells revealed that tPSBikDDA was 3.7-fold more efficient in gene transfection than PS-BikDDA.

Recent studies demonstrated that polymersomes could serve as excellent gene delivery carrier(Lomas et al. 2010). The comparison of the formulated P(OEG $10 \mathrm{MA})_{20}-\mathrm{PDPA}_{100}$ polymersomes with its targeted form demonstrated that targeted $\mathrm{P}\left(\mathrm{OEG}_{10} \mathrm{MA}\right)_{20}-\mathrm{PDPA} 100$ polymersomes could be used for in vitro cell specific gene delivery. 


\subsection{BikDDA loaded tPS (tPS-BikDDA) increase the levels of Bik target genes and cell death activity in the LNCaP cell line}

The relative Bik/18sRNA mRNA expression of $\mathrm{LNCaP}$ cells treated and non-treated with tPSBikDDA were analyzed using qRT-PCR. The results showed that LNCaP cells treated with tPSBikDDA expressed the Bik gene twice as much as the untreated cells (Figure 8a). Cell viability analysis indicates that almost $50 \%$ of the LNCaP cell lines transfected with tPS-BikDDA were not vital after $72 \mathrm{~h}$ (Figure 8b). These results confirm that tPS-BikDDA is effective in increasing the Bik gene expression into $\mathrm{LNCaP}$ cells to induce cell death.

\section{Conclusion}

The purpose of this study was to develop novel peptide-copolymer conjugation strategies and demonstrate the application of pro-apoptotic BikDDA-loaded polymersomes as targeted gene delivery tools for prostate cancer cells. Peptide-copolymer conjugation was achieved by the reaction between maleimide-thiol groups and using SMCC as a linker between the peptide cysteine residual and a primary amine expressed in the copolymer. SMCC has recently been employed for conjugation in aqueous medium (El-Sayed et al. 2016) but we developed a novel reaction strategy which takes place in organic solvent (DMF) and demonstrated the peptide-copolymer conjugate by fluorometric HPLC detection.

The TEM images of electroporated and purified polymersomes proved that the integrity of the polymersome membrane structure was preserved after electroporation, whilst the transfection experiments indicated that BikDDA remained stable after electroporation without any degradation. Both these results are in agreement with our previously published work (Wang et al. 2012). 
Given that peptide563 has high binding affinity to PSMA protein, which is expressed on the surface of prostate cancer cells (such as $\mathrm{LNCaP}$ ), it was used to direct $\mathrm{P}\left(\mathrm{OEG}_{10} \mathrm{MA}\right)_{20}-\mathrm{PDPA}_{100}$ polymersomes specifically to LNCaP cells. Polymersomes decorated on their surface with peptide563, revealed specificity and high binding affinity to PSMA-expressing LNCaP cells in comparison to PNT1A cell line. PSMA-targeting peptide-decorated polymersomes were prepared and their cellular uptake by LNCaP and PNT1A cells were demonstrated. The targeted polymersomes not only exhibited a higher cellular uptake by LNCaP cells, but also were not internalized by PNT1A cells. This data might suggest that targeting peptide "peptide563" acts as a steric barrier against the polymersome internalization by PNT1A cells.

The overexpression of BikDD in various human cancer cells lines results in strong apoptosis induction (Beer and Raghavan 2000; Li et al. 2003), and BikDD expression was recently shown to kill androgen dependent prostate cancer LNCaP cell lines (Lang et al. 2011). To the best of our knowledge, no studies have been performed using BikDDA as a potential therapeutic for prostate cancer. Our findings show that LNCaP cells treated with tPS-BikDDA expressed Bik gene twice as much as untreated LNCaP cells after $72 \mathrm{~h}$. Moreover, tPS-BikDDA decrease cell viability of $\mathrm{LNCaP}$ cells by $50 \%$ in comparison to untreated $\mathrm{LNCaP}$ cells.

This study proposed different peptide-copolymer conjugation strategies and demonstrates the effectiveness of targeted $\mathrm{P}\left(\mathrm{OEG}_{10} \mathrm{MA}\right)_{20}-\mathrm{PDPA}_{100}$ polymersomes loaded with BikDDA to enable cell specific delivery with enhanced gene transfection ability. This represents a novel, nontoxic and highly effective gene therapy strategy for the prostate cancer LNCaP cell line.

\section{Supporting Information}

Supporting Information is available from the Wiley Online Library or from the author. 


\section{Acknowledgments}

The authors would like to thank Prof. Alethea Tabor and Dr. Robin Bofinger for their contribution at synthesis/purification of cyanine terminated peptide563 and Ayla Burcin Asutay for her technical support in flow cytometry. This research was partially funded by Scientific and Technological Research Council of Turkey (TUBITAK, grant number 213M760). Umut Can Oz is also thankful for a fellowship (2214-A) from the TUBITAK. The authors declare no conflict of interest.

\section{Conflict of Interest}

The authors declare no conflict of interest.

\section{References}

Ahmed F, Pakunlu RI, Srinivas G, et al (2006) Shrinkage of a rapidly growing tumor by drugloaded polymersomes: pH-triggered release through copolymer degradation. Mol Pharm 3:340-350.

Banik BL, Fattahi P, Brown JL (2016) Polymeric nanoparticles: the future of nanomedicine. WIREs Nanomedicine and Nanobiotechnology 8:271-299.

Beer T, Raghavan D (2000) Chemotherapy for hormone-refractory prostate cancer: Beauty is in the eye of the beholder. Prostate 45:184-193.

Chinnadurai G, Vijayalingam S, Rashmi R (2009) BIK, the founding member of the BH3-only family proteins: mechanisms of cell death and role in cancer and pathogenic processes. Oncogene 27:S20-S29. 
Colley HE, Hearnden V, Avila-Olias M, et al (2014) Polymersome-mediated delivery of combination anticancer therapy to head and neck cancer cells: $2 \mathrm{D}$ and $3 \mathrm{D}$ in vitro evaluation. Mol Pharm 11:1176-1188.

Discher BM, Won YY, Ege DS, et al (1999) Polymersomes: Tough vesicles made from diblock copolymers. Science (80- ) 284:1143-1146.

El-Sayed NS, Shirazi AN, El-Meligy MG, et al (2016) Design, synthesis, and evaluation of chitosan conjugated GGRGDSK peptides as a cancer cell-targeting molecular transporter. Int J Biol Macromol 87:611-622.

Elsässer-Beile U, Bühler P, Wolf P(2009) Targeted therapies for prostate cancer against the prostate specific membrane antigen. Curr Drug Targets 10:118-25.

Erdem M, Erdem S, Sanli O, et al (2014) Up-regulation of TGM2 with ITGB1 and SDC4 is important in the development and metastasis of renal cell carcinoma. Urol Oncol Semin Orig Investig 32:25.e13-25.e20.

Gaitzsch J, Appelhans D, Wang L, et al (2012) Synthetic bio-nanoreactor: Mechanical and chemical control of polymersome membrane permeability. Angew Chemie - Int Ed $51: 4448-4451$.

Gaitzsch J, Delahaye M, Poma A, et al (2016) Comparison of metal free polymer-dye conjugation strategies in protic solvents. Polym Chem 7:3046-3055.

Huang WC, Chen YC, Hsu YH, et al (2015) Development of a diagnostic polymersome system for potential imaging delivery. Colloids Surfaces B Biointerfaces 128:67-76. 
International Agency for Research on Cancer (2012) Prostate Cancer Estimated Incidence, Mortality and Prevalence Worldwide in 2012. In: GLOBOCAN 2012 Cancer Fact Sheets

Jiao S, Wu M, Ye F, et al (2014) BikDDA, a mutant of Bik with longer half-life expression protein, can be a novel therapeutic gene for triple-negative Breast Cancer. PLoS One 17;9(3):e92172.

Lang JY, Hsu JL, Meric-Bernstam F, et al (2011) BikDD eliminates breast cancer initiating cells and synergizes with lapatinib for breast cancer treatment. Cancer Cell 20:341-356.

Li L-Y, Dai H-Y, Yeh F-L, et al (2010) Targeted hepatocellular carcinoma proapoptotic BikDD gene therapy. Oncogene 30:1773.

Li YM, Wen Y, Zhou BP, et al (2003) Enhancement of Bik Antitumor Effect by Bik Mutants. Cancer Res 63:7630

Lomas H, Canton I, MacNeil S, et al (2007) Biomimetic pH sensitive polymersomes for efficient DNA encapsulation and delivery. Adv Mater 19:4238-4243.

Lomas H, Du J, Canton I, et al (2010) Efficient encapsulation of plasmid DNA in pH-sensitive PMPC-PDPA polymersomes: Study of the effect of PDPA block length on copolymer-DNA binding affinity. Macromol Biosci 10:513-530.

Lomas H, Massignani M, Abdullah KA, et al (2008) Non-cytotoxic polymer vesicles for rapid and efficient intracellular delivery. Faraday Discuss 139:143-159.

Lopresti C, Massignani M, Fernyhough C, et al (2011) Controlling polymersome surface topology at the nanoscale by membrane confined polymer/polymer phase separation. ACS 
Nano 5:1775-1784.

Mustapa MFM, Grosse SM, Kudsiova L, et al (2009) Stabilized Integrin-Targeting Ternary LPD (Lipopolyplex) Vectors for Gene Delivery Designed To Disassemble Within the Target Cell. Bioconjug Chem 20:518-532.

Oz UC, Kucukturkmen B, Ozkose UU, et al (2019) Design of colloidally stable and non-toxic PEtOx based polymersomes for cargo molecule encapsulation. ChemNanoMat 5:766-775.

Rameez S, Alosta H, Palmer AF (2008) Biocompatible and biodegradable polymersome encapsulated hemoglobin: A potential oxygen carrier. Bioconjug Chem 19:1025-1032.

Robertson JD, Rizzello L, Avila-Olias M, et al (2016) Purification of Nanoparticles by Size and Shape. Sci Rep 6:27494.

Ruoslahti E (2012) Peptides as Targeting Elements and Tissue Penetration Devices for Nanoparticles. Adv Mater 24:3747-3756.

Shen D, Xie F, Edwards WB (2013) Evaluation of Phage Display Discovered Peptides as Ligands for Prostate-Specific Membrane Antigen (PSMA). PLoS One 8:e68339.

Simón-Gracia L, Hunt H, Scodeller P, et al (2016) iRGD peptide conjugation potentiates intraperitoneal tumor delivery of paclitaxel with polymersomes. Biomaterials 104:247-257.

Simon-Gracia L, Hunt H, Scodeller PD, et al (2016) Paclitaxel-loaded Polymersomes for Enhanced Intraperitoneal Chemotherapy. Mol Cancer Ther 15:670-680.

Tian X, Nyberg S, S Sharp P, et al (2015) LRP-1-mediated intracellular antibody delivery to the Central Nervous System. Sci Rep 5:11990. https://doi.org/https://doi.org/10.1038/srep11990 
Wang L, Chierico L, Little D, et al (2012) Encapsulation of biomacromolecules within polymersomes by electroporation. Angew Chemie - Int Ed 51:11122-11125.

Xie X, Kong Y, Tang H, et al (2014) Targeted BikDD Expression Kills Androgen-Dependent and Castration-Resistant Prostate Cancer Cells. Mol Cancer Ther 13:1813.

Xie X, Xia W, Li Z, et al (2007) Targeted Expression of BikDD Eradicates Pancreatic Tumors in Noninvasive Imaging Models. Cancer Cell 12:52-65.

Zou Y, Peng H, Zhou B, et al (2002) Systemic tumor suppression by the proapoptotic gene bik. Cancer Res 62:8-12 


\section{Figures}

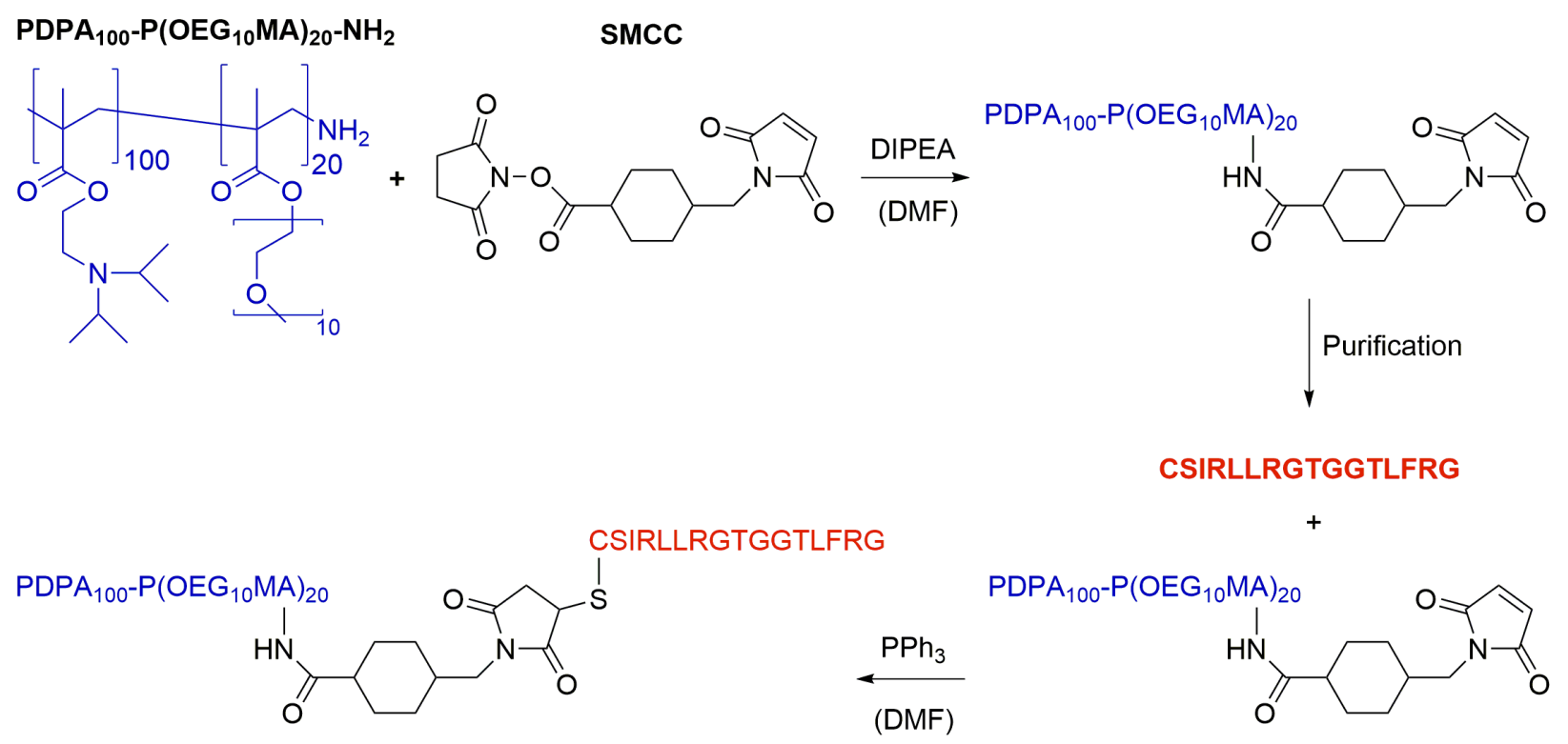

Figure 1. $\mathrm{P}\left(\mathrm{OEG}_{10} \mathrm{MA}\right)_{20}-\mathrm{PDPA}_{100}$ conjugation with cysteine terminated Peptide563 using SMCC as a crosslinker. 

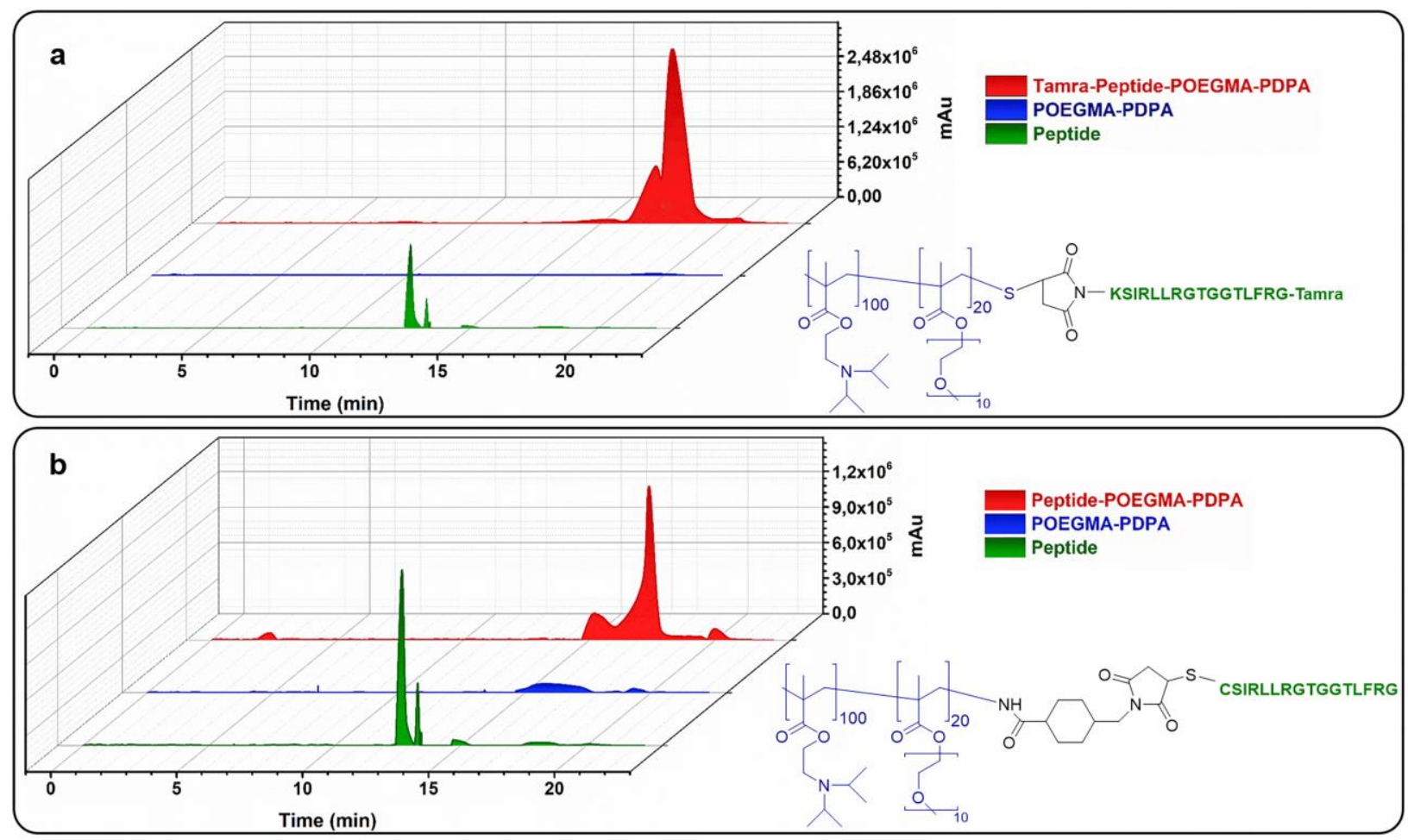

Figure 2. HPLC chromatograms and chemical structures of peptide-copolymer conjugates. $\mathrm{P}\left(\mathrm{OEG}_{10} \mathrm{MA}\right)_{20}-\mathrm{PDPA}_{100}$ successfully conjugated with Tamra labeled maleimide-peptide653 (b) and cysteine-peptide653 (a).

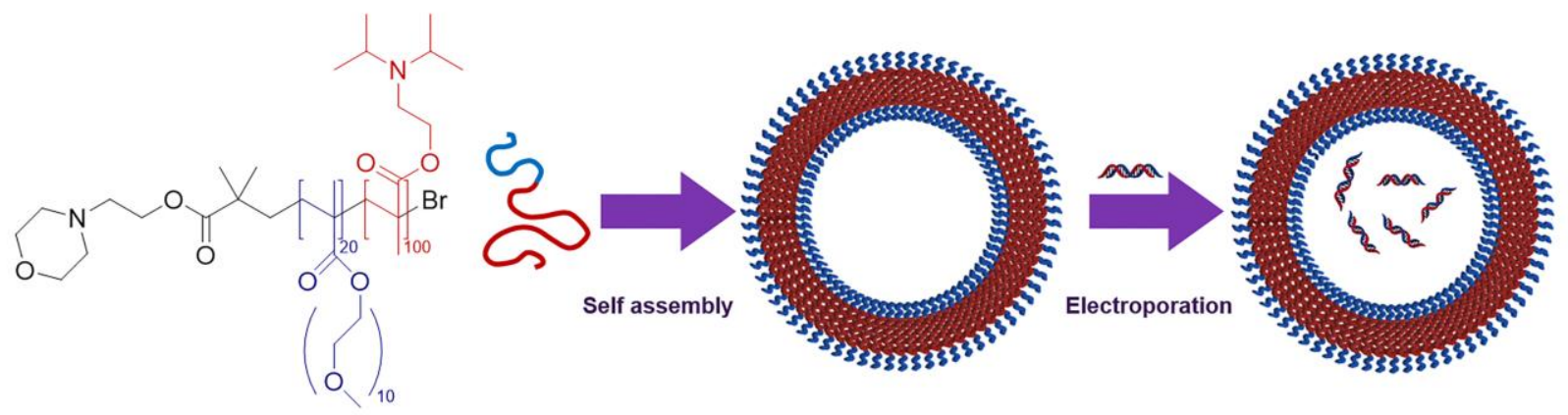

Figure 3. Scheme of the formation and BikDDA loading into $\mathrm{P}\left(\mathrm{OEG}_{10} \mathrm{MA}\right)_{20}-\mathrm{PDPA}_{100}$ polymersomes. 

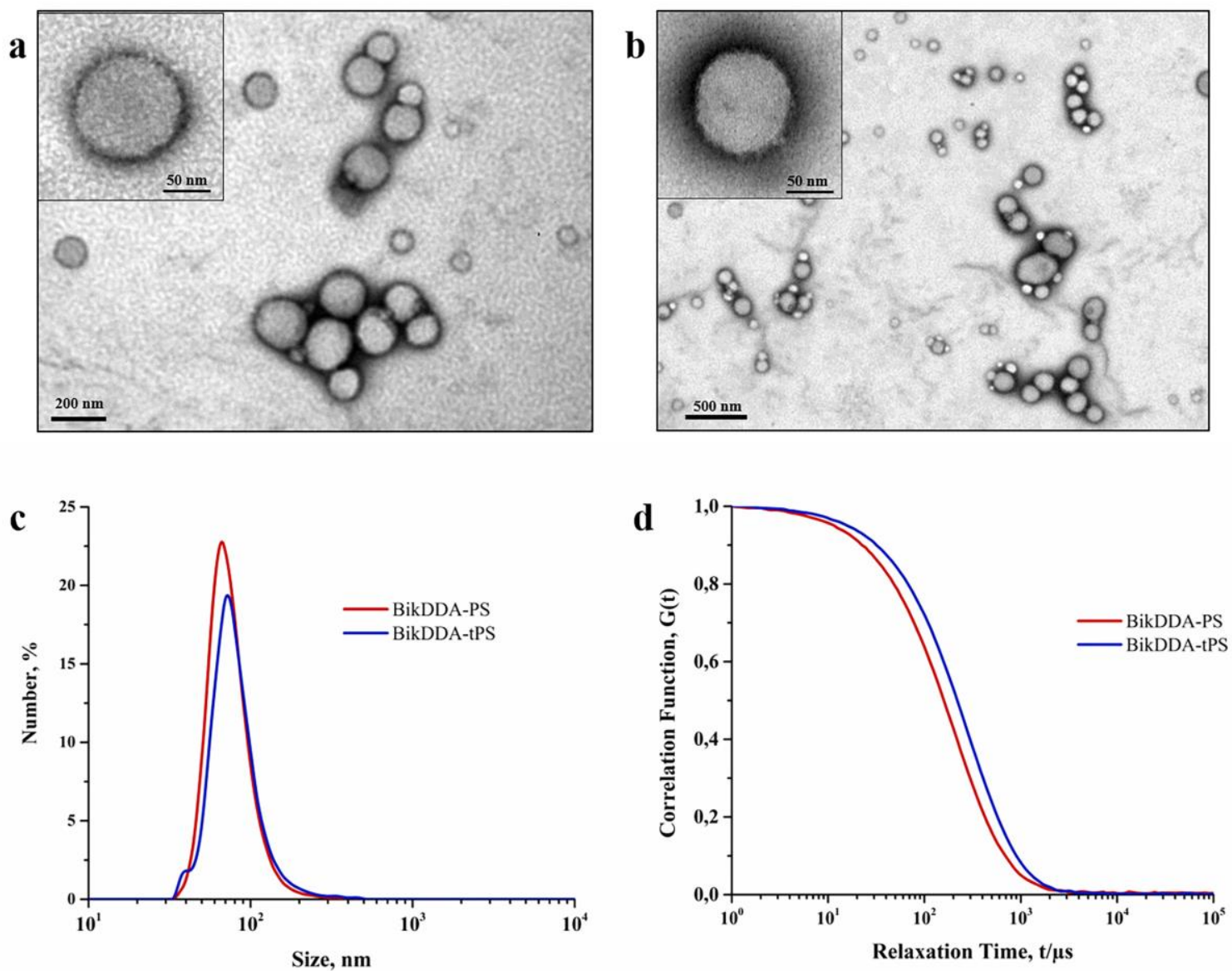

Figure 4. The TEM images of PS-BikDDA (a) and tPS-BikDDA (b). Size distribution profiles (c) and correlation functions (d) of polymersomes, obtained by DLS. 
a

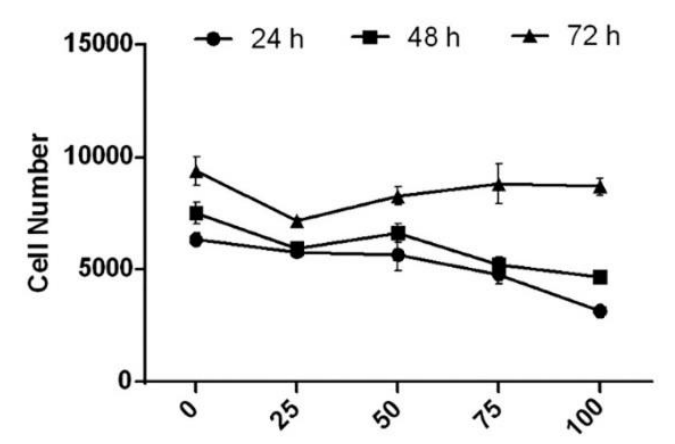

POEGMA $_{20}-$ PDPA $_{100}$ polymer $(\mu \mathrm{g} / \mathrm{ml})$ b
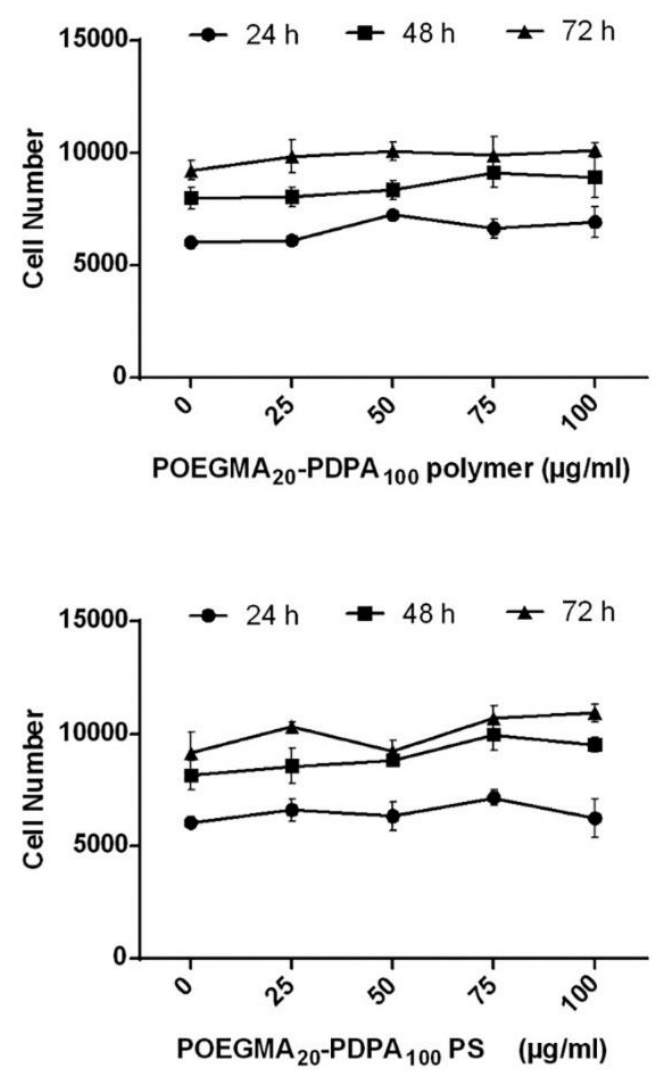

Figure 5. An MTS analysis of healthy epithelial prostate cell line PNT1A (a) and prostate cancer cell line $\mathrm{LNCaP}(\mathbf{b})$. The cells seeded on 96 -well plates at $5 \times 10^{3}$ cells/well density were treated with $25,50,75$ and $100 \mu \mathrm{g} / \mathrm{mL}$ of $\mathrm{P}\left(\mathrm{OEG}_{10} \mathrm{MA}\right)_{20}-\mathrm{PDPA}_{100}$ polymer and polymersomes in RPMI 1640 medium supplemented with $10 \%$ FBS for 24,48 and $72 \mathrm{~h}$. Cell viability was assessed at each $24 \mathrm{~h}$ interval by measuring the absorbance change using a microplate reader at $490 \mathrm{~nm}$. 

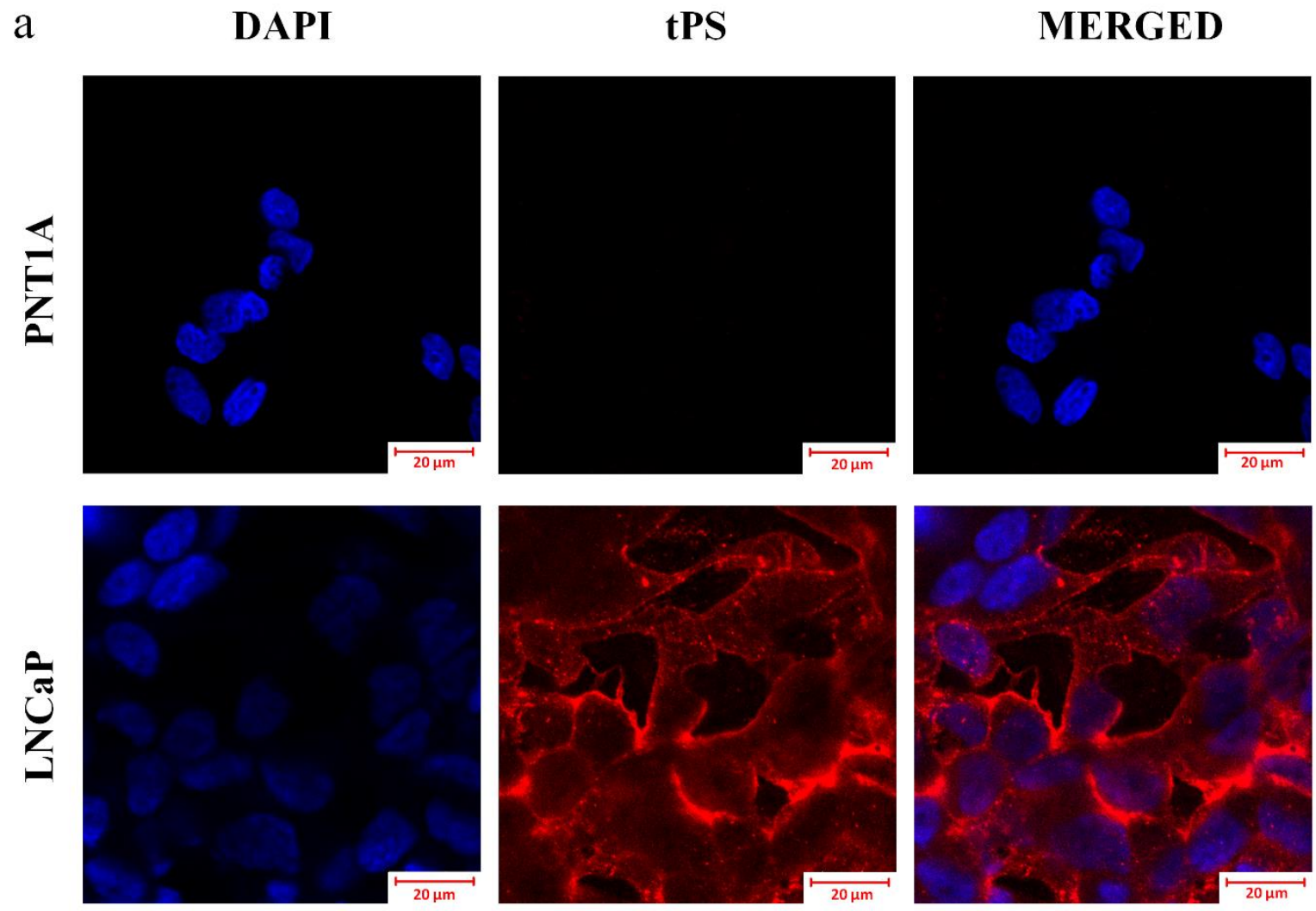

b
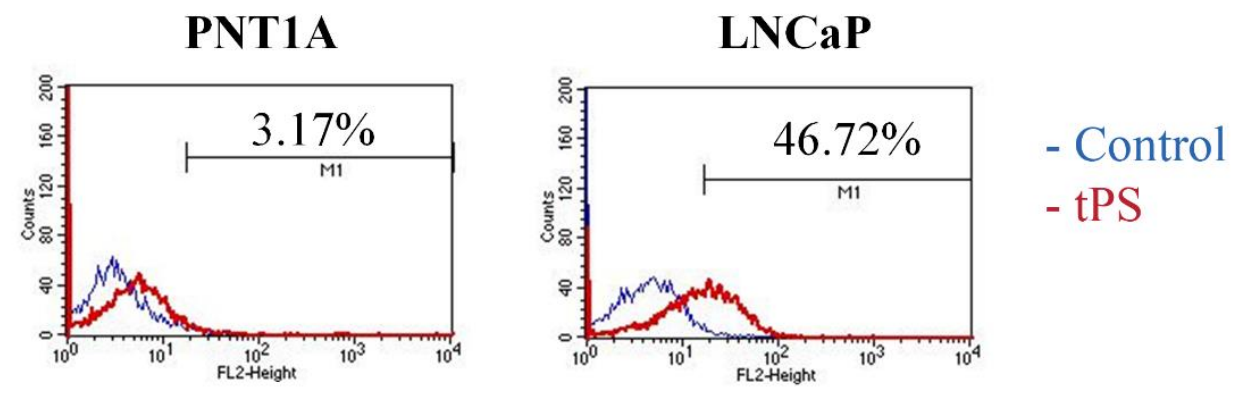

Figure 6. Confocal fluorescence microscopy images taken using $63 \times$ objective after tPS incubation of PNT1A (top row) and LNCaP (bottom row) cells for $4 \mathrm{~h}$ (a). The cell nuclei were stained blue with DAPI. Scale Bar: $20 \mu \mathrm{m}$. Flow cytometric detection of tPS cellular uptake by PNT1A (left) and LNCap (right) following the $4 \mathrm{~h}$ incubation at $37^{\circ} \mathrm{C}$ (b). 
a
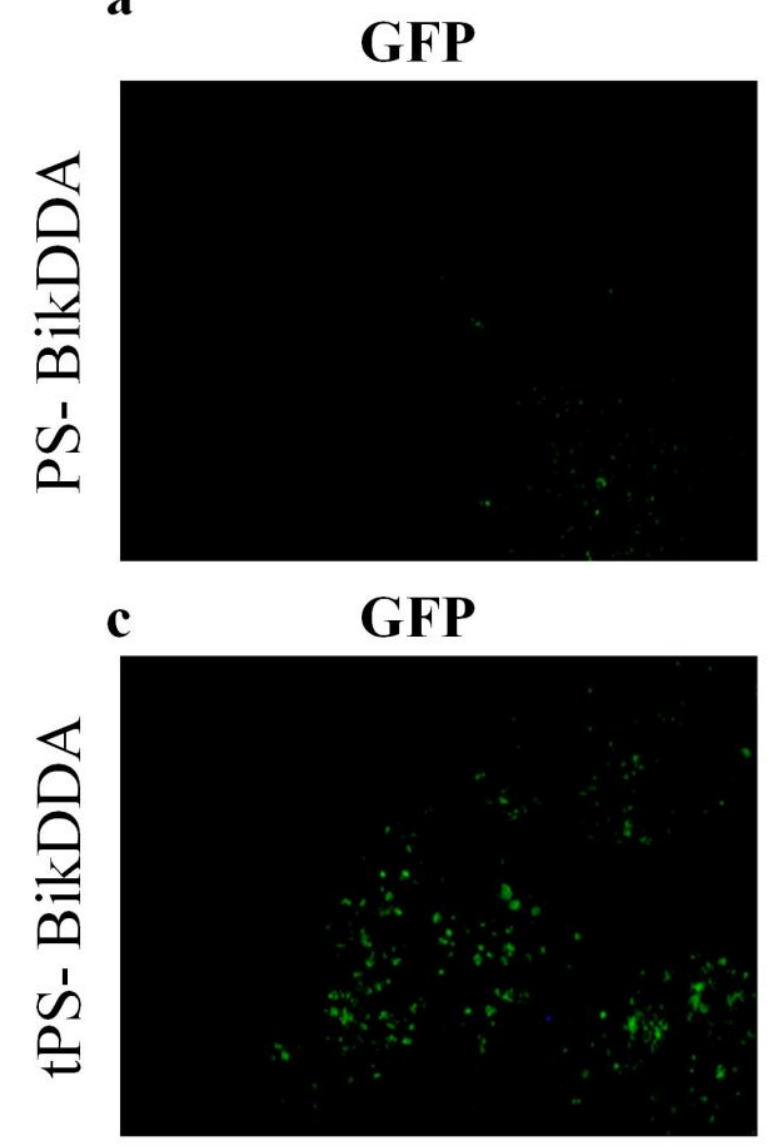

b

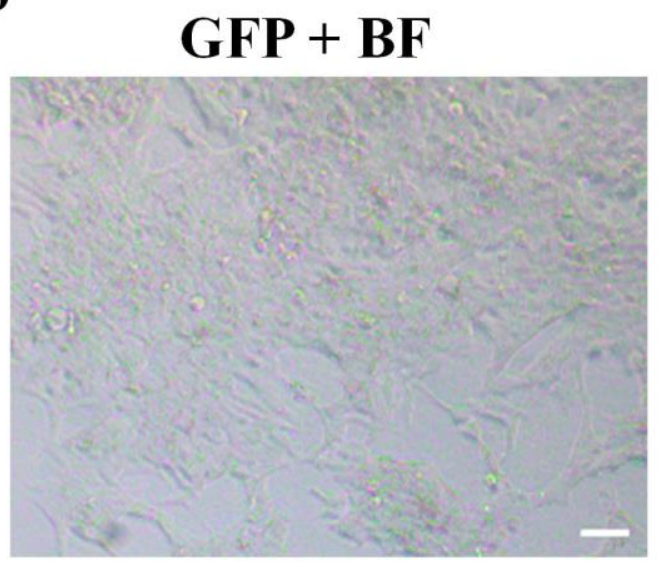

d

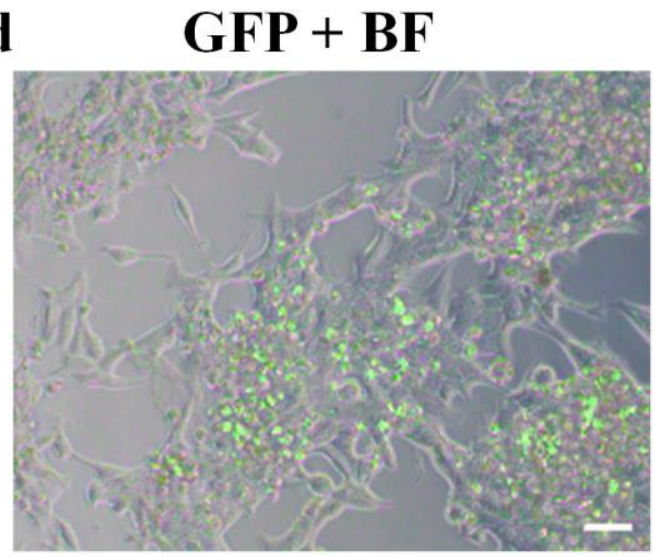

Figure 7. Transfection efficiency of pEGFP-BikDDA plasmid in LNCaP cell lines for PSBikDDA and tPS-BikDDA. The transfection efficiency was determined by counting the GFPpositive cells under a fluorescence microscope and the results were expressed as the percentage of total cells. Four random fields with $>100$ cells/field were captured under fluorescence microscopy at $20 \times$ objectives and quantified. The images of the LNCaP cells show the transfection efficiency of PS-BikDDA under GFP filter (a) and merged images of bright field (BF) and GFP filter (b) at $72 \mathrm{~h}$. Also, the LNCaP cells show the transfection efficiency of tPS-BikDDA under GFP filter (c) and merged images of BF and GFP filter (d) are given at $72 \mathrm{~h}$. Scale Bar: $50 \mu \mathrm{m}$. 

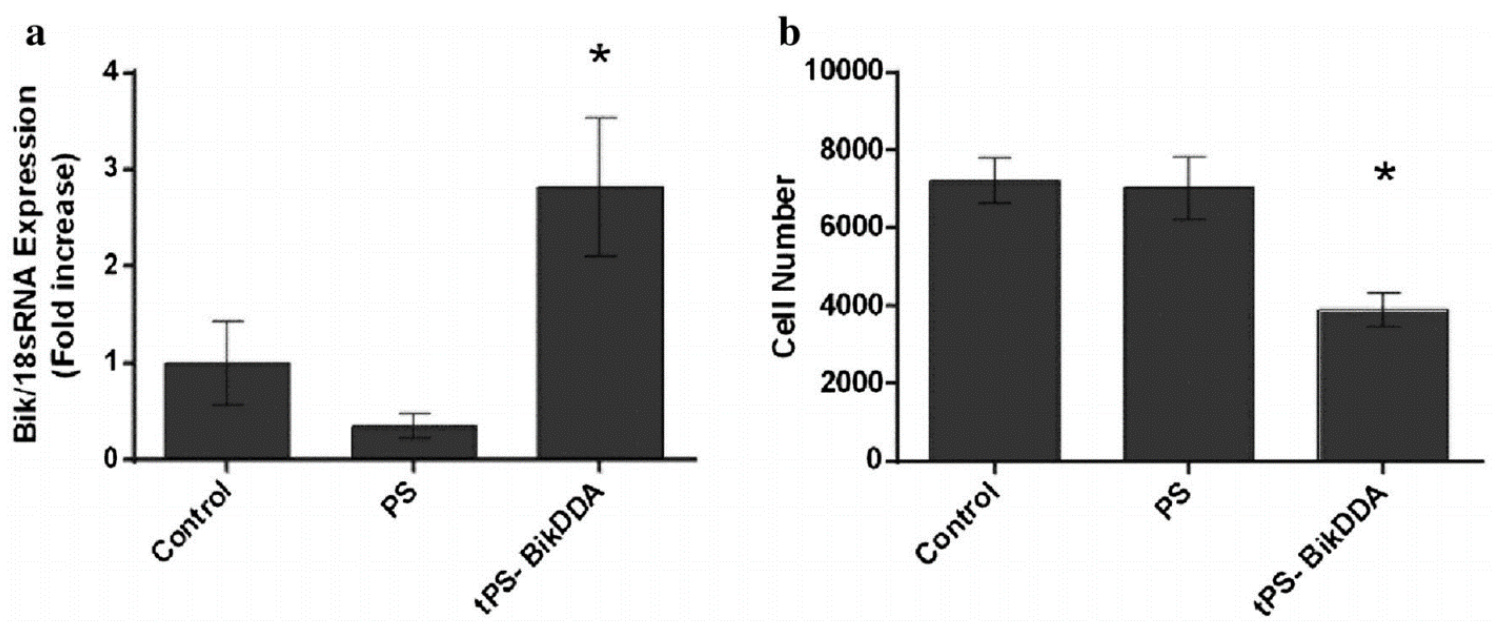

Figure 8. Fold increase of relative Bik/18sRNA mRNA expression using real time PCR (a) and cell viability analysis with MTS (b) in LNCaP cell lines transfected with BikDDA gene loaded tPS $\left(2 \mu \mathrm{g}\right.$ BikDDA $\left./ 3 \times 10^{5}\right)$, non-encapsulated $\mathrm{P}\left(\mathrm{OEG}_{10} \mathrm{MA}\right)_{20}-\mathrm{PDPA}_{100}$ polymersome (PS) and non-treated LNCaP cells (Control). The data represents the means of three independent experiments. ${ }^{*}$ denotes significant difference compared with the control $(\mathrm{p}<0.05)$. 